\title{
Chemical Communications
}

\section{COMMUNICATION}

\section{Steric effects determine the mechanisms of reactions between bis( $N$-heterocyclic carbene)-nickel( 0 ) complexes and aryl halides}

Received 00th January 20xx, Accepted 00th January 20xx

\author{
DOI: $10.1039 / x 0 \times x 00000 x$
}

www.rsc.org/

Computational investigations of the reactions of $\left[\mathrm{Ni}(\mathrm{NHC})_{2}\right]$ complexes with aryl halides show that the outcomes are governed by the steric impact of the ligand ( $\mathrm{NHC}=\mathrm{N}$-heterocyclic carbene). Small ligands permit facile oxidative addition, leading to $\mathrm{Ni}$ complexes, while larger NHC ligands prevent coordination of the aryl halide and favour the halide abstraction to form $\mathrm{Ni}$.

Nickel catalysis has seen rapid development within the past few years, especially in the activation of less reactive functional groups, ${ }^{1,2}$ and in reductive cross-coupling ${ }^{3}$ and tandem photocatalysis/cross-coupling reactions. ${ }^{4}{ }^{5} \mathrm{~A}$ distinguishing feature of nickel is its ability to access +1 and +3 oxidation states relatively easily, as well as the 0 and +2 oxidation states typically implicated in cross-coupling. This behaviour is not well understood, and there is a pressing need for detailed mechanistic investigations to support and underpin new developments in synthetic chemistry. We seek a detailed, quantitative understanding of oxidative addition reactions involving nickel species that are relevant to catalysis (Figure 1). Two key issues are: (i) the rate of the reaction will determine whether the overall catalytic reaction is feasible on a reasonable timescale; and (ii) the ratio of $\mathrm{Ni}^{\prime}$ to $\mathbf{N i l l}$ produced is important because of the unclear role of $\mathrm{Ni}^{1}$ in catalysis. ${ }^{6-8}$

We have carried out kinetic studies of the oxidative addition of aryl (pseudo)halides to [Ni(COD)(dppf)], showing that $\mathrm{Ni}^{\mathrm{l}}$ arises from oxidative addition to form [Ni(Ar)X(dppf)], followed by comproportionation (dppf $=1,1^{\prime}$-diphenylphosphinoferrocene) (Figure 1 (a)) ; ${ }^{9}[\mathrm{Ni}(\mathrm{Ar})(\mathrm{dppf})]$ complexes, which are plausible intermediates in this process, have recently been documented. ${ }^{10}$ We have computationally evaluated $\left[\mathrm{Ni}\left(\mathrm{PR}_{3}\right)_{4}\right]$ systems (studied experimentally by Kochi), ${ }^{11}$ and showed that the $\mathrm{Ni}^{1}$ to $\mathrm{Ni}^{11}$ ratio is determined by

a. WestCHEM Department of Pure and Applied Chemistry, University of Strathclyde, 295 Cathedral Street, Glasgow, G1 1XL, UK. david.nelson@strath.ac.uk.

b. Institute of Chemical Research of Catalonia (ICIQ), The Barcelona Institute of Technology (BIST), Avgda. Països Catalans, Tarragona, Spain.

c. Departamente de Química, Universitat Autònoma de Barcelona, 08193 Bellaterra, Spain

† Electronic Supplementary Information (ESI) available: Additional data and results from computational calculations. See DOI: 10.1039/x0xx00000x.

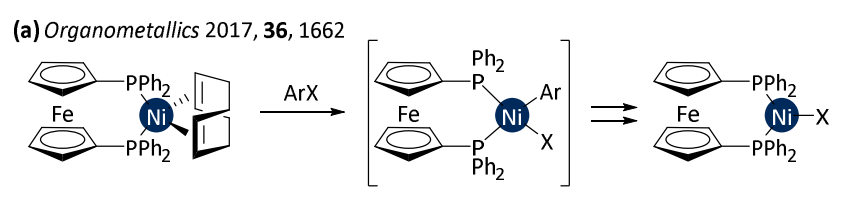

Rate: $\mathrm{Cl}>\mathrm{Br}>\mathrm{I}>\mathrm{OTs}>\mathrm{OCO}_{2} \mathrm{Et}>\mathrm{OTf}>\mathrm{OCONEt}_{2}>\mathrm{OSO}_{2} \mathrm{NMe}_{2}>\mathrm{OPiv}>\mathrm{OMe} \sim \mathrm{F}$

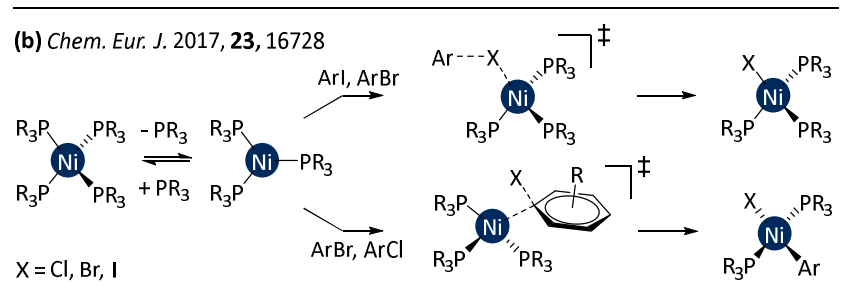

$\mathrm{PR}_{3}=\mathrm{PMe}_{3}, \mathrm{PMe}_{2} \mathrm{Ph}, \mathrm{PMePh}_{3}, \mathrm{PPh}_{3}$

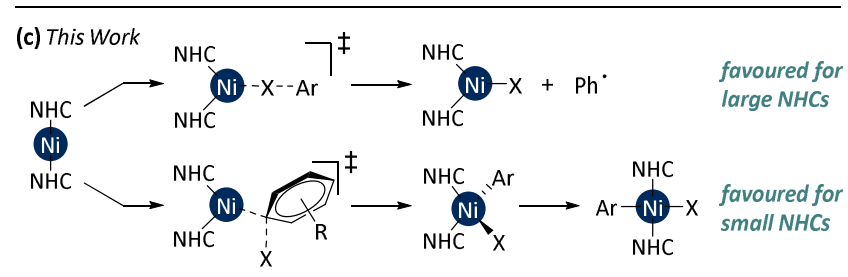

Figure 1. Our studies of oxidative addition to complexes bearing (a) dppf, (b) monodentate phosphines, and (c) N-heterocyclic carbenes.

the competition between halide abstraction via $\left[\mathrm{Ni}\left(\mathrm{PR}_{3}\right)_{3}(\mathrm{XAr})\right]$ and oxidative addition to $\left[\mathrm{Ni}\left(\mathrm{PR}_{3}\right)_{3}\right]$ (Figure 1 (b)). ${ }^{12}$ These two systems show divergent behaviour as a result of their different ligand sets; understanding ligand effects will allow for rational and judicious ligand selection for catalytic applications. ${ }^{13}$ Baird and Budzelaar have shown that halide abstraction from alkyl halides by $\left[\mathrm{Ni}\left(\mathrm{PPh}_{3}\right)_{4}\right]$ can account for experimental observations with this system. ${ }^{14}$

Nickel-NHC complexes have been applied widely in catalysis. ${ }^{15}\left[\mathrm{Ni}(\mathrm{NHC})_{2}\right]$ complexes show intriguing reactivity with aryl halides: [Ni(ITMe $)_{2}$ ] (A-1) undergoes oxidative addition to form [ $\left.\mathrm{Ni}^{\prime \prime}(\mathrm{Ar}) \mathrm{X}(\mathrm{ITMe})_{2}\right],{ }^{16,}{ }^{17}$ yet $\left[\mathrm{Ni}(\mathrm{IMes})_{2}\right]$ (B-1) and close analogues generate $\left[\mathrm{NiX}(\mathrm{NHC})_{2}\right]$ plus arene. $\$, 16,18$ $\left[\left\{\mathrm{Ni}\left(\mathrm{I}^{\mathrm{P} P r}\right)_{2}\right\}_{2}(\mathrm{COD})\right]$ is well-behaved in a range of oxidative addition reactions, ${ }^{19-21}$ with few exceptions. ${ }^{\$,} 22$ Here, we use calculations to demonstrate that the reaction mechanisms for 
the reactions of aryl halides with $\left[\mathrm{Ni}\left(\mathrm{NHC}_{2}\right]\right.$ complexes are determined by the steric impact of the NHC ligand (Figure 1 (c)); this may influence the choice of NHC substituents for catalytic applications in the future.

Four systems were considered computationally: the [Ni(ITMe $)_{2}$ (A-1) and [Ni(IMes) $)_{2}$ (B-1) systems have been studied experimentally, while $\left[\mathrm{Ni}(\mathrm{IXY})_{2}\right](\mathbf{C}-\mathbf{1})$ and $\left[\mathrm{Ni}(\mathrm{IPhen})_{2}\right]$ (D-1) are smaller analogues of B-1 that were studied computationally to gain further insight into the selectivity of the reactions. ${ }^{\S}$ In all cases, the combination of $\left[\mathrm{Ni}(\mathrm{COD})_{2}\right]$ and $\mathrm{NHC}$ leads to $\left[\mathrm{Ni}(\mathrm{NHC})_{2}\right]$ as the lowest energy species, with $[\mathrm{Ni}(\mathrm{COD})(\mathrm{NHC})]$ significantly higher in energy (see Table S1). ${ }^{+}$ All free energies quoted in this manuscript are relative to $\left[\mathrm{Ni}(\mathrm{NHC})_{2}\right]$ (enthalpies can be found in Table S2). +

The reactions of A-1 are profiled in Figure 2. The formation of $\eta^{2}$-complex A-2 is slightly exergonic, and there is essentially no barrier to the subsequent irreversible oxidative addition event, ultimately forming trans-[Ni(Ph)X(ITMe $\left.)_{2}\right](A-4)$. Halide abstraction would proceed via coordination of the halide (A-5), which is slightly endergonic, followed by an open shell singlet transition state (TS-A-5-6) with a barrier dependent on the identity of the halide. The phenyl radical generated in this process can then abstract a hydrogen atom from the THF solvent, as modelled in our previous study. ${ }^{12}$ However, the oxidative addition pathway is far more favourable, and therefore the $\mathrm{Nill}$ products (A-4) will dominate in all cases.

The free energy profiles for the reactions of [Ni(IMes) 2 (B1) (Figure 3) are very different. The formation of the necessary $\eta^{2}$-complex (B-2) is very endergonic $\left(\mathrm{G}_{\mathrm{rel}} \approx 22-24 \mathrm{kcal} \mathrm{mol}^{-1}\right)$, which would then be followed by a small (or no) barrier for oxidative addition (TS-B-2-3). The molecular structure of B-2$\mathrm{Br}$ is presented in Figure 4; there is evidently a significant steric clash between the IMes ligands; the energetic penalty to distort the $\mathrm{Ni}($ IMes) 2 fragment to the same geometry as in $\mathbf{B - 2}$ is significant $\left(\Delta \mathrm{E}=38-40 \mathrm{kcal} \mathrm{mol}^{-1}\right.$; see Table S3). This steric interaction can be avoided if the aryl halide coordinates the nickel centre via the halide atom (B-5; $\left.\mathrm{G}_{\mathrm{rel}} \approx 0-8 \mathrm{kcal} \mathrm{mol}^{-1}\right)$. Halide abstraction can take place with a barrier that is a function of the halide identity (TS-B-5-6); for iodobenzene the reaction is essentially barrierless, while bromobenzene and chlorobenzene undergo halide abstraction via transition states that are far lower in energy than the corresponding $\eta^{2}$ complexes $\mathbf{B - 2 - B r}$ and $\mathbf{B - 2 - C l}$.

An alternative reaction pathway via a mono-NHC

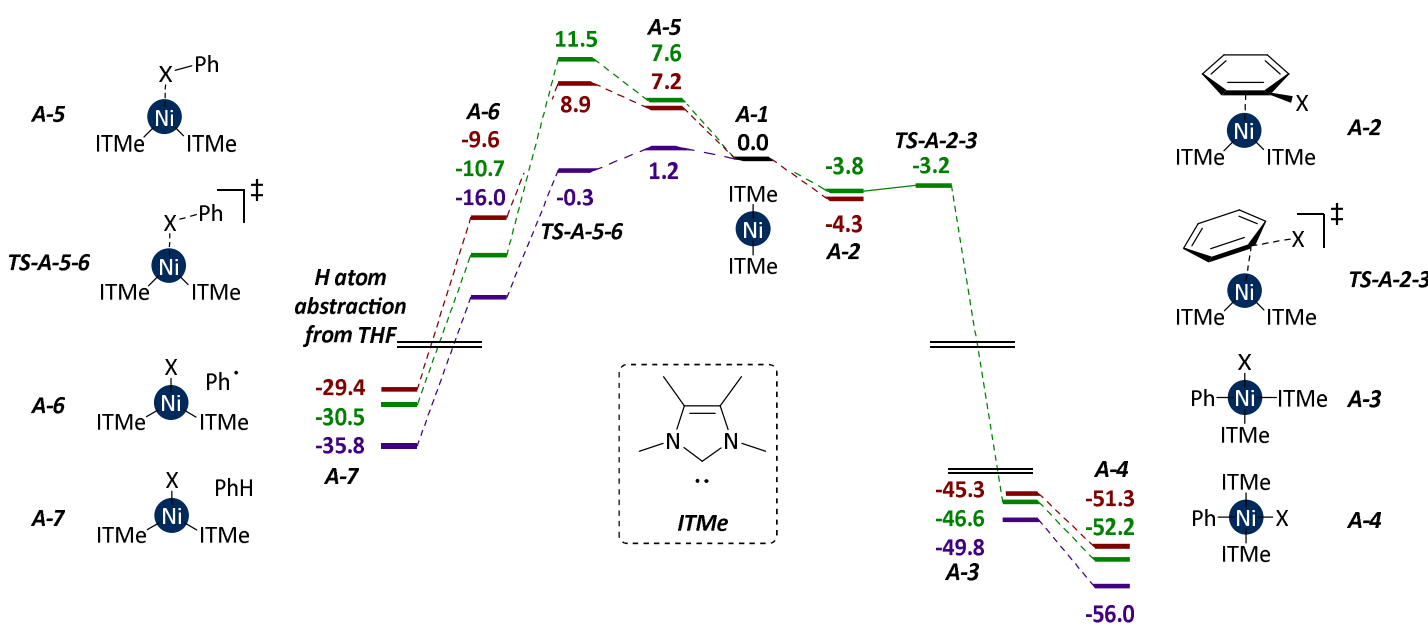

Figure 2. Free energy profiles for the reactions of $\left[\mathrm{Ni}(\mathrm{ITMe})_{2}\right](\mathbf{A}-\mathbf{1})$ with $\mathrm{PhCl}$ (green), $\mathrm{PhBr}$ (orange), and $\mathrm{Phl}$ (purple). Energies are quoted in kcal mol-1 in THF relative to A-1.

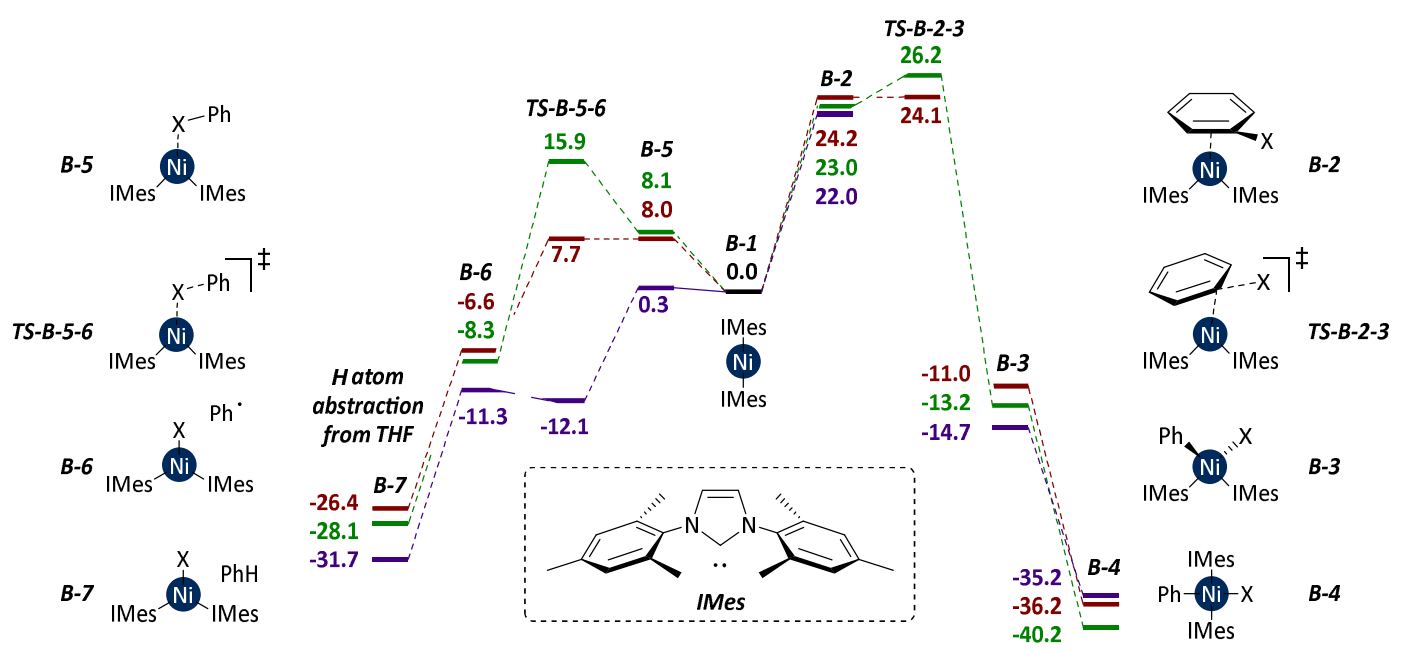

Figure 3. Free energy profiles for the reactions of [ $\left.\mathrm{Ni}(\mathrm{IMes})_{2}\right]$ (B-1) with $\mathrm{PhCl}$ (green), $\mathrm{PhBr}$ (orange), and Phl (purple). Energies are quoted in kcal mol-1 in THF relative to B-1. 


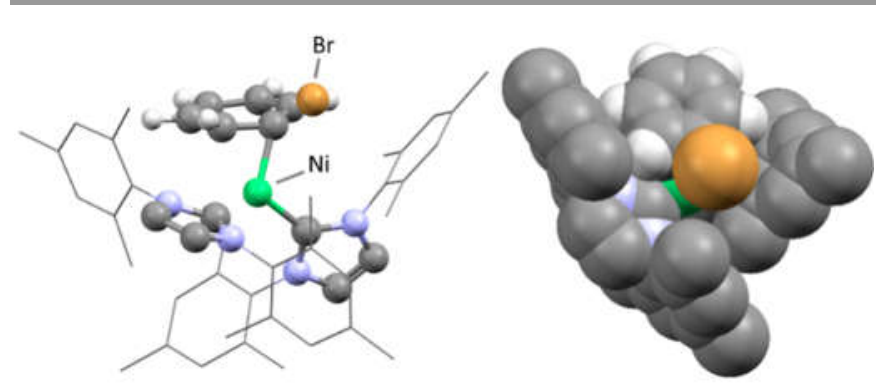

Figure 4. (a) Molecular structure and (b) spacefill model of $\left[\mathrm{Ni}(\mathrm{IMes})_{2}\left(\eta^{2}-\mathrm{PhBr}\right)\right]$. Most hydrogen atoms are omitted for clarity.

[Ni(IMes)] complex was considered, because these species are known to be competent cross-coupling catalysts, ${ }^{23}$ using chlorobenzene as the substrate (Figure 5). The low free energy of B-1 means that this pathway is not competent under conditions where B-1 can form (TS-B-2'-3' $-\mathbf{C l}$ has $\mathrm{G}_{\mathrm{rel}}=27.0$

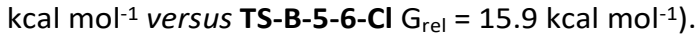

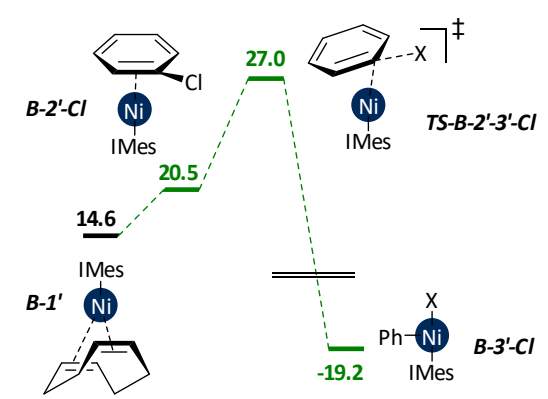

Figure 5. Free energy profile for the reactions of [Ni(COD)(IMes)] (B-1') with $\mathrm{PhCl}$. Energies are quoted in $\mathrm{kcal} \mathrm{mol}^{-1}$ in THF relative to $\mathbf{B}-\mathbf{1}$.

The key determinant of reactivity in these systems is the steric impact of the ligand; the effect of aryl halide structure on reaction selectivity is essentially negligible for chlorobenzene versus bromobenzene versus iodobenzene, unlike the reactions of $\left[\mathrm{Ni}\left(\mathrm{PR}_{3}\right)_{4}\right]$ complexes. ${ }^{11}, 12$ These new insights provide us with the opportunity to predict the reactivity of species that have not yet been studied experimentally. The results above show that the outcomes of the reactions of $\left[\mathrm{Ni}(\mathrm{NHC})_{2}\right]$ with aryl halides can be understood by comparing the relative energies of the oxidative addition transition state (TS-X-2-3) and the halide abstraction transition state (TS-X-5-6). Two further ligands were considered: IXY does not have the para-methyl groups present on IMes, while IPhen has all three methyl groups removed from each of the $\mathrm{N}$-aryl substituents. The reactions of the corresponding $\left[\mathrm{Ni}(\mathrm{NHC})_{2}\right]$ complexes with chlorobenzene were considered.

$\left[\mathrm{Ni}(\mathrm{IXY})_{2}\right] \quad(\mathbf{C}-\mathbf{1})$ behaves almost exactly like the IMes congener (B-1), with the halide abstraction transition state (TSC-5-6, Grel $=14.6 \mathrm{kcal} \mathrm{mol}^{-1}$ ) more than $10 \mathrm{kcal} \mathrm{mol}^{-1}$ lower in energy than the oxidative addition transition state (TS-C-2-3, $\left.\mathrm{G}_{\mathrm{rel}}=25.6 \mathrm{kcal} \mathrm{mol}^{-1}\right)$. The full free energy profile can be found in Figure S1 in the Supporting Information. The wingtip substitution of $\mathrm{N}$-aryl NHCs therefore makes little or no difference to the energetics of the reactions of the $\left[\mathrm{Ni}(\mathrm{NHC})_{2}\right]$ complexes with aryl halides.

[Ni(IPhen) $)_{2}$ (D-1) bears a ligand that is sufficiently unhindered that the reactivity is dramatically different to that of $\left[\mathrm{Ni}(\mathrm{IMes})_{2}\right]$ (B-1) (Figure 6). The energetic profile for halide abstraction (via TS-D-5-6-Cl) is very similar to that for the IMes congener (via TS-B-5-6-Cl; see Figure 3), suggesting that the nickel centres in B-1 and D-1 have similar electronic properties. However, the formation of $\eta^{2}$-complex $\mathbf{D}-\mathbf{2}-\mathbf{C l}$ and the subsequent oxidative addition transition state TS-DS-2-3-Cl are significantly lower in energy than the IMes congeners B-2$\mathbf{C l}$ and TS-B-2-3-Cl; the transition state is ca. $23 \mathrm{kcal} \mathrm{mol}^{-1}$ lower in energy for IPhen. These data show that for [Ni(IPhen) $)_{2}$ (D-1), oxidative addition is far more favourable than halide abstraction; D-1 will therefore behave in a similar manner to $\left[\mathrm{Ni}(\mathrm{ITMe})_{2}\right]$ (A-1). The difference in behaviour between complexes IPhen and IXY shows that the orthosubstituents primarily determine the steric bulk of $\mathrm{N}$-aryl NHCs.

In conclusion, this study demonstrates two important points. Firstly, smaller NHCs favour oxidative addition to form $\mathrm{Nill}$ complexes that are likely intermediates in cross-coupling catalytic cycles, while larger NHCs will favour halide abstraction to form $\mathrm{Ni}^{\prime}$; coordination of the halide precludes

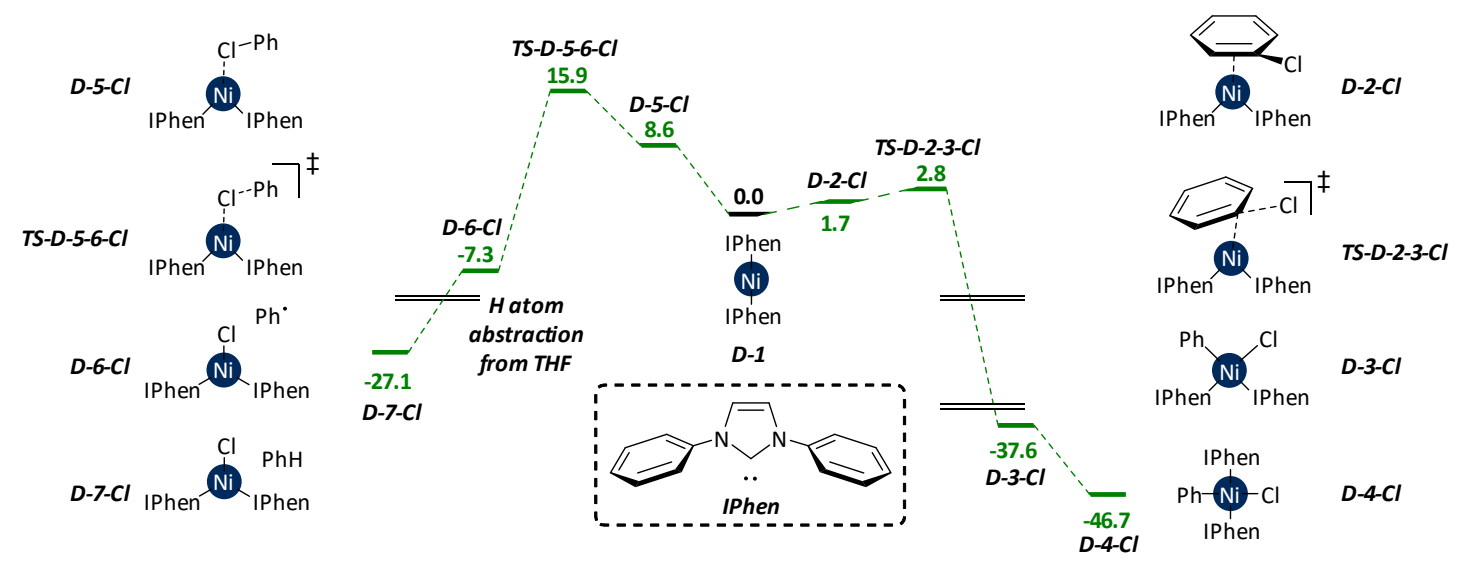

Figure 6. Free energy profiles for the reactions of $\left[\mathrm{Ni}(\mathrm{IPhen})_{2}\right](\mathrm{D}-\mathbf{1})$ with $\mathrm{PhCl}$. Energies are quoted in $\mathrm{kcal}_{\mathrm{mol}}^{-1}$ in $\mathrm{THF}$ relative to $\mathrm{D}-1$. 
the need to introduce the steric interactions between NHCs that occur when the geometry is distorted to form $\eta^{2}$ complexes. Secondly, this study suggests that mono-NHC nickel complexes may be a better choice for many catalytic reactions because no (or less) steric interaction is introduced when an $n^{2}$-haloarene is formed. If the data from Figure 4 are reevaluated in the context of a reaction that has a 1:1 IMes: $\left[\mathrm{Ni}(\mathrm{COD})_{2}\right]$ ratio (rather than $2: 1$ ), with $\left[\mathrm{Ni}(\mathrm{COD})_{2}\right]$ having $\mathrm{G}_{\text {rel }}=$ 0 , the oxidative addition transition state TS-B-2'-3'-Cl has $\mathrm{G}_{\text {rel }}=$ $11.3 \mathrm{kcal} \mathrm{mol}^{-1}$, which is representative of a facile oxidative addition reaction. Of course, the ambiguous role of $\mathrm{Ni}^{1}$ means that further work is ongoing in our research groups to fully understand the roles and reactivity of nickel complexes in various oxidation states.

DJN thanks the University of Strathclyde for funding (Chancellor's Fellowship 2014 - present; Global Engagements Fund 2015; WestCHEM PECRE 2015). FM thanks the CERCA Programme, the Generalitat de Catalunya and MINECO (Grant CTQ-2017-87792-R) for funding. We are grateful to Dr Ignacio Funes-Ardoiz (ICIQ) for helpful discussions.

\section{Conflicts of interest}

There are no conflicts to declare.

\section{Notes and references}

$\ddagger$ Computational Details: B3LYP-D3 calculations with a triple- $\zeta$ basis set plus polarization and diffusion shells in THF solution Full computational details supplied in the ESIt. A data set collection of computational results is available in the ioChem-BD repository. ${ }^{24}$

$\S$ Abbreviations: ITMe $=1,3,4,5$-tetramethylimidazol-2-ylidene; IMes = 1,3-bis (2,4,6-trimethyl-phenyl)imidazol-2-ylidene; $\mathrm{I}^{\mathrm{P} P}=$ 1,3-diisopropylimidazol-2-ylidene; IXy = 1,3-bis(2,6-dimethylphenyl)imidazol-2-ylidene; IPhen = 1,3-diphenylimidazol-2-ylidene.

1. B. M. Rosen, K. W. Quasdorf, D. A. Wilson, N. Zhang, A.-M. Resmerita, N. K. Garg and V. Percec, Chem. Rev., 2010, 111, 1346-1416.

2. P. Álvarez-Bercedo and R. Martin, J. Am. Chem. Soc., 2010, 132, 17352-17353.

3. D. J. Weix, Acc. Chem. Res., 2015, 48, 1767-1775.

4. J. C. Tellis, C. B. Kelly, D. N. Primer, M. Jouffroy, N. R. Patel and G. A. Molander, Acc. Chem. Res., 2016, 49, 14291439.

5. M. H. Shaw, J. Twilton and D. W. C. MacMillan, J. Org. Chem., 2016, 81, 6898-6926.

6. L. M. Guard, M. Mohadjer Beromi, G. W. Brudvig, N. Hazari and D. J. Vinyard, Angew. Chem. Int. Ed., 2015, 54, 13352-13356.

7. I. Kalvet, Q. Guo, G. J. Tizzard and F. Schoenebeck, ACS Catal., 2017, 7, 2126-2132.

8. C. M. Lavoie, R. McDonald, E. R. Johnson and M. Stradiotto, Adv. Synth. Catal., 2017, 359, 2972-2980.

9. S. Bajo, G. Laidlaw, A. R. Kennedy, S. Sproules and D. J. Nelson, Organometallics, 2017, 36, 1662-1672.

10. M. Mohadjer Beromi, G. Banerjee, G. W. Brudvig, N. Hazari and B. Q. Mercado, ACS Catal., 2018, 8, 2526-2533.
11.

T. T. Tsou and J. K. Kochi, J. Am. Chem. Soc., 1979, 101, 6319-6332.

12. I. Funes-Ardoiz, D. J. Nelson and F. Maseras, Chem. Eur. J., 2017, 23, 16728-16733.

13. D. Balcells and A. Nova, ACS Catal., 2018, 8, 3499-3515.

14. R. Kehoe, M. Mahadevan, A. Manzoor, G. McMurray, P. Wienefeld, M. C. Baird and P. H. M. Budzelaar, Organometallics, 2018, DOI: 10.1021/acs.organomet.8b00244.

15. A. P. Prakasham and P. Ghosh, Inorg. Chim. Acta, 2014, 431, 61-100.

16. K. Zhang, M. Conda-Sheridan, S. R. Cooke and J. Louie, Organometallics, 2011, 30, 2546-2552.

$17 . \quad$ D. S. McGuinness, K. J. Cavell, B. W. Skelton and A. H. White, Organometallics, 1999, 18, 1596-1605.

18. S. Miyazaki, Y. Koga, T. Matsumoto and K. Matsubara, Chem. Commun., 2010, 46, 1932-1934.

19. T. Schaub and U. Radius, Chem. Eur. J., 2005, 11, 50245030.

20. T. Zell, M. Feierabend, B. Halfter and U. Radius, J. Organomet. Chem., 2011, 696, 1380-1387.

21. T. Zell, P. Fischer, D. Schmidt and U. Radius, Organometallics, 2012, 31, 5065-5073.

22. J. A. Hatnean, M. Shoshani and S. A. Johnson, Inorg. Chim. Acta, 2014, 422, 86-94.

$23 . \quad$ S. G. Rull, I. Funes-Ardoiz, C. Maya, F. Maseras, M. R. Fructos, T. R. Belderrain and M. C. Nicasio, ACS Catal., 2018, 8, 3733-3742.

24. M. Álvarez-Moreno, C. de Graaf, N. López, F. Maseras, J. M. Poblet and C. Bo, J. Chem. Inf. Model., 2015, 55, 95103. 